Check for updates

Cite this: RSC Adv., 2017, 7, 21430

\title{
Ir-phosphate cocatalyst for photoelectrochemical water oxidation using $\alpha-\mathrm{Fe}_{2} \mathrm{O}_{3}^{\dagger}$
}

\begin{abstract}
Ahamed Irshad (D) and Nookala Munichandraiah*
$\alpha-\mathrm{Fe}_{2} \mathrm{O}_{3}$ is an ideal photoanode for solar water oxidation owing to its visible light absorbing capability, suitable valence band position, low cost, high abundance, non-toxicity and eco-friendliness. However, the reported efficiencies are very low due to the poor kinetics of water oxidation by photogenerated holes on $\alpha-\mathrm{Fe}_{2} \mathrm{O}_{3}$. In the present study, an $\alpha-\mathrm{Fe}_{2} \mathrm{O}_{3}$ electrode is obtained by heating a film of Fe which is prepared by the electrochemical reduction of $\mathrm{Fe}^{2+}$ ions. Film thickness and calcination temperature are carefully optimized to get a maximum photoresponse in neutral phosphate solution. In order to improve the water oxidation kinetics and reduce the charge carrier recombination, an iridium-phosphate (Ir-Pi) catalyst is electrodeposited on the surface of $\alpha-\mathrm{Fe}_{2} \mathrm{O}_{3}$. Ir-Pi is found to reduce the OER onset potential by $350 \mathrm{mV}$, and enhances the photocurrent density by 3 times at $1.23 \mathrm{~V}$ vs. RHE.
\end{abstract}

Received 4th January 2017 Accepted 9th April 2017

DOI: 10.1039/c7ra00102a

rsc.li/rsc-advances been attributed to a low rate constant of water oxidation reaction (WOR) by photogenerated holes, and short hole diffusion length $(2-4 \mathrm{~nm})$ which allows only holes close to the surface to participate in the reaction. ${ }^{7}$ Issues related with short hole diffusion lengths have been largely addressed by nanostructuring of the photoelectrodes. ${ }^{8}$ However, surface and bulk recombination losses still limit the overall performance of hematite based photoanodes. Recent studies suggest that the light driven oxygen evolution reaction (OER) at $\alpha-\mathrm{Fe}_{2} \mathrm{O}_{3}$ is sluggish, and most of the photogenerated holes simply undergo recombination with electrons. ${ }^{9}$ The recombination shifts the photocurrent onset away from the flatband potential, thus, limiting the water splitting efficiency. It has been shown that this loss process can be reduced by interfacing hematite electrodes with OER cocatalysts., ${ }^{9,10}$

Recently, electrochemical water oxidation at low overpotentials was demonstrated by our group using an amorphous iridium-phosphate (Ir-Pi) catalyst electrodeposited onto carbon paper electrode. ${ }^{11}$ It is anticipated that the photogenerated holes in $\alpha-\mathrm{Fe}_{2} \mathrm{O}_{3}$ are capable of driving water oxidation reaction by Ir-Pi electrocatalyst. Herein, we report the electrodeposition of Ir-Pi catalyst on the surface of $\alpha-\mathrm{Fe}_{2} \mathrm{O}_{3}$, which in turn is prepared by heating an electrodeposited Fe film on FTO coated glass. The hybrid Ir-Pi- $\mathrm{Fe}_{2} \mathrm{O}_{3}$ is used for the photoelectrochemical water oxidation in neutral phosphate buffer solution. Ir-Pi reduces the onset potential of OER by $350 \mathrm{mV}$ and enhances the photocurrent by three times at $1.23 \mathrm{~V} v \mathrm{v}$. RHE.

\section{Experimental section}

\subsection{Reagents, materials and characterization studies}

Analytical grade $\mathrm{KH}_{2} \mathrm{PO}_{4}, \mathrm{~K}_{2} \mathrm{HPO}_{4}, \mathrm{FeSO}_{4} \cdot 7 \mathrm{H}_{2} \mathrm{O}$ (Merck) and $\mathrm{IrCl}_{3}$ (Aldrich) were used as received. All solutions were 
prepared using double distilled water. Phosphate buffer solution was prepared by mixing calculated volumes of $0.1 \mathrm{M}$ $\mathrm{KH}_{2} \mathrm{PO}_{4}$ and $0.1 \mathrm{M} \mathrm{K}_{2} \mathrm{HPO}_{4}$ solutions. The solution $\mathrm{pH}$ was maintained at 7.0, unless otherwise stated. The physical characterization studies of the materials were carried out by using scanning electron microscopy (SEM), energy dispersive X-ray analysis (EDXA), X-ray photoelectron spectroscopy (XPS), diffuse reflectance spectroscopy and Raman spectroscopy. For SEM images, Ultra 55 scanning electron microscope equipped with EDXA system at $20 \mathrm{kV}$ was used. Surface compositions of the electrodeposits were analyzed by XPS using SPECS GmbH spectrometer (Phoibos 100 MCD Energy Analyzer) with $\mathrm{Mg} \mathrm{K}_{\alpha}$ radiation. Raman spectra were collected using LabRam HR (UV) system at an excitation wavelength of $532 \mathrm{~nm}$. UV-Vis diffuse reflectance spectroscopic studies were carried out by Perkin Elmer Lambda 750 spectrophotometer with pure $\mathrm{BaSO}_{4}$ as the reference. The optical band gap was calculated from Tauc plot for which $\alpha$ value was extracted from reflectance using KubelkaMunk model. Electrochemical deposition and photoelectrochemical studies were conducted using PARC EG\&G potentiostat/galvanostat model Versastat II as the electrochemical measurement unit and Xe lamp as the light source. The light from the source was calibrated to 1 Sun intensity $(100$ $\mathrm{mW} \mathrm{cm}^{-2}$ ) using a photodiode power meter (Thorlab, S120B) and a standard solar cell. $\mathrm{Fe}_{2} \mathrm{O}_{3}$ or Ir-Pi- $\mathrm{Fe}_{2} \mathrm{O}_{3}\left(\right.$ area $\left.=1 \mathrm{~cm}^{2}\right)$ as the working electrode, saturated calomel electrode (SCE) reference and a large area Pt counter electrode were used. Photoelectrochemical studies were carried out by linear sweep voltammetry at $50 \mathrm{mV} \mathrm{s}^{-1}$ in $0.1 \mathrm{M}$ neutral phosphate solution under dark, and illumination from both front and back sides of the coating. Applied bias photon-to-current efficiencies (ABPE) of the electrodes were calculated from voltammograms, assuming $100 \%$ faradaic efficiency. Incident photon-to-current efficiency (IPCE) was measured using Oriel IQE 200 equipped with a Xe lamp and Cornerstone monochromator. Electrochemical impedance spectra were recorded by $\mathrm{CH}$ Instruments potentiostat/galvanostat model CHI 608C, which was coupled to a frequency response analyzer. An ac perturbation of $10 \mathrm{mV}$ was applied at a frequency of $10 \mathrm{kHz}$ and impedance was measured as a function of applied potential. Mott-Schottky plot generated from the impedance data was used for the determination of flat band potential. Current density values are reported on the basis of geometrical area. Potential values are converted to reversible hydrogen electrode (RHE) scale using the equation, $E_{\mathrm{RHE}}=E_{\mathrm{SCE}}$ $+E_{\mathrm{SCE}}^{0}+0.059 \times \mathrm{pH}$, where $E_{\mathrm{SCE}}$ is the measured potential using SCE reference and $E_{\mathrm{SCE}}^{0}$ is the standard potential of SCE at $25^{\circ} \mathrm{C}$ $(0.242 \mathrm{~V})$, unless otherwise stated.

\subsection{Electrochemical deposition of Fe film}

Iron film was electrodeposited onto fluorine doped tin oxide (FTO) coated conducting glass plate (TISXZ006, sheet resistance $<10 \Omega \mathrm{sq}^{-1}$ ) as reported in the literature. ${ }^{12}$ Prior to the deposition, FTO glass plates were cleaned thoroughly by sonication for $15 \mathrm{~min}$ each in water, acetone and isopropanol. The FTO glass slides were dried in Ar flow and electrical contact was made through a $\mathrm{Cu}$ wire attached to the conducting side of FTO glass using Ag paste. The exposed area was $1 \mathrm{~cm}^{2}$ and remaining part of the electrode was covered with PTFE tape. Electrodeposition was carried out in a glass cell with FTO as the working electrode, a large Pt foil as counter electrode and a SCE as the reference. The electrolyte was freshly prepared $10 \mathrm{mM}$ $\mathrm{FeSO}_{4} \cdot 7 \mathrm{H}_{2} \mathrm{O}$ solution in water. Electrodeposition was carried out at $-1.05 \mathrm{~V} v s$. SCE for different time intervals in the range 1-15 min. After deposition, electrodes were gently rinsed with water, dried in Ar flow and stored in vacuum desiccators.

\subsection{Preparation of $\alpha-\mathrm{Fe}_{2} \mathrm{O}_{3}$}

The electrodeposited Fe film was converted to $\alpha-\mathrm{Fe}_{2} \mathrm{O}_{3}$ by thermal treatment. For this, Fe film coated FTO glass plates were separated from Cu contact wires. Silver paste used for the contact was completely removed using acetone to avoid any possible diffusion of Ag during high temperature heating. The Fe-FTO plate was kept in an alumina boat and heated in air at different temperatures and durations. Temperature was in the range of 300-900 ${ }^{\circ} \mathrm{C}$ and heating time was 1-6 h. Formation of $\alpha-\mathrm{Fe}_{2} \mathrm{O}_{3}$ was monitored by XRD and Raman spectroscopy.

\subsection{Electrodeposition of Ir-Pi on $\alpha-\mathrm{Fe}_{2} \mathrm{O}_{3}$}

Amorphous iridium-phosphate (Ir-Pi) was deposited onto $\alpha-\mathrm{Fe}_{2} \mathrm{O}_{3}$ coated FTO electrodes using electrochemical method as reported in the case of Ir-Pi deposition on carbon electrodes. ${ }^{\mathbf{1 1}}$ The electrolyte was $0.5 \mathrm{mM} \mathrm{IrCl}_{3}$ in $0.1 \mathrm{M}$ potassium phosphate solution (pH 7.0). Deposition was carried out $1.0 \mathrm{~V} v s$. SCE for different time intervals, typically in the range of 0-40 $\mathrm{min}$ without stirring the solution. After deposition, electrodes were thoroughly rinsed with double distilled water, dried at $60{ }^{\circ} \mathrm{C}$ for $1 \mathrm{~h}$ and stored in a desiccator.

\section{Results and discussions}

\subsection{Crystallinity}

Electrodeposition of Fe film on FTO and its conversion to $\alpha-\mathrm{Fe}_{2} \mathrm{O}_{3}$ was confirmed by XRD analysis. In the case of Fe film (Fig. 1(ii)), peaks at $45.8^{\circ}, 65.8^{\circ}$ and $82.9^{\circ}$ are observed which differ from the XRD pattern of the bare FTO substrate (Fig. 1(i)). These peaks are due to the reflections from (110), (200) and (211) planes of cubic Fe metal, thus, indicating the formation of Fe deposit by the electrochemical reduction of $\mathrm{Fe}^{2+}$ ions. ${ }^{12}$ It is to be noted that most of the FTO peaks are absent for Fe-FTO because thick layer of Fe was used for the XRD studies. On heating in air above $300{ }^{\circ} \mathrm{C}$, Fe deposit is converted into $\alpha-\mathrm{Fe}_{2} \mathrm{O}_{3}$, and the crystallinity improves with heating temperature and time. The XRD pattern of the Fe film after heating at $600{ }^{\circ} \mathrm{C}$ for $2 \mathrm{~h}$ is shown in Fig. 1(iii). The peaks from the cubic structure of $\mathrm{Fe}$ are absent and new peaks appear. These peaks are assigned to diffractions from (104), (110), (113), (024), (018), (300) and (220) planes of $\alpha-\mathrm{Fe}_{2} \mathrm{O}_{3} \cdot{ }^{13}$ No other major peaks can be found indicating the phase purity of $\alpha-\mathrm{Fe}_{2} \mathrm{O}_{3}$ film formed by the calcination of electrodeposited Fe. The XRD pattern for Ir-Pi$\mathrm{Fe}_{2} \mathrm{O}_{3}$ (Fig. 1(iv)) shows only the peaks from bare $\alpha-\mathrm{Fe}_{2} \mathrm{O}_{3}$ and no other peaks are observed for Ir-Pi, suggesting the amorphous nature of the electrodeposited Ir-Pi. Similarly, very thick Ir-Pi 


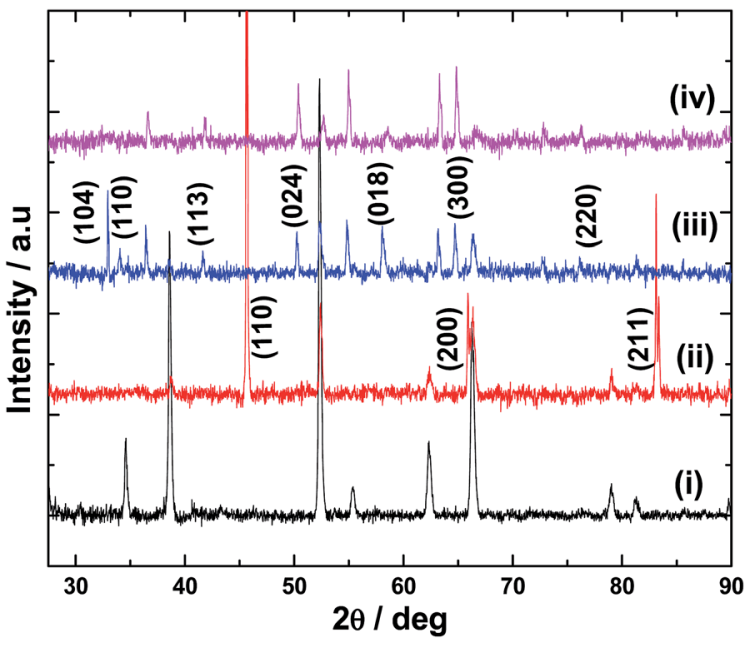

Fig. 1 XRD patterns for (i) FTO and FTO coated with (ii) Fe, (iii) $\mathrm{Fe}_{2} \mathrm{O}_{3}$ and (iv) Ir-Pi- $\mathrm{Fe}_{2} \mathrm{O}_{3}$.

deposited directly onto FTO substrate also shows amorphous feature (Fig. S1 of the ESI†). This is again in accordance with the results reported for the Ir-Pi deposition on carbon paper substrate. ${ }^{11}$

\subsection{Morphology}

The morphology of the electrodeposit was studied by SEM. As it is seen from Fig. 2a, the electrodeposited Fe film has cubic shaped particles. These particles are fused in many regions forming clusters. No preferential growth direction is observed and they are randomly distributed. On the other hand, $\mathrm{Fe}_{2} \mathrm{O}_{3}$ formed after heating $\mathrm{Fe}$ at $600^{\circ} \mathrm{C}$ for $2 \mathrm{~h}$ shows entirely different morphology (Fig. 2b) where only lumps are found. These lumps have size in the range of 200 to $800 \mathrm{~nm}$. SEM image after Ir-Pi deposition (Fig. 2c) shows that these $\mathrm{Fe}_{2} \mathrm{O}_{3}$ lumps are covered with sheets of Ir-Pi catalyst. These sheets are folded and wrapped on the surface of $\mathrm{Fe}_{2} \mathrm{O}_{3}$. However, Ir-Pi on $\mathrm{Fe}_{2} \mathrm{O}_{3}$ is slightly different in morphology from the reported Ir-Pi on carbon paper. ${ }^{11}$ This could be due to large difference in the conductivity as well as surface features of the carbon paper and $\mathrm{Fe}_{2} \mathrm{O}_{3}$ substrates. In addition, a relatively higher potential and deposition time was used for Ir-Pi deposition on $\mathrm{Fe}_{2} \mathrm{O}_{3}$ in view of large ohmic drop in the film due to poor electronic conductivity of Fe oxides. Similarly, TEM and HRTEM images clearly show a sharp interface between crystalline $\mathrm{Fe}_{2} \mathrm{O}_{3}$ particle and amorphous Ir-Pi catalyst layer (Fig. S2 $\dagger$ ).

\subsection{Raman spectra}

Raman spectra were recorded for all the samples. The asdeposited Fe film doesn't exhibit any Raman active bands (Fig. 3(i)). However, on heating at $600{ }^{\circ} \mathrm{C}$ for $2 \mathrm{~h}$, peaks associated with $\alpha-\mathrm{Fe}_{2} \mathrm{O}_{3}$ are observed (Fig. 3(ii)). Seven optical modes of even symmetry $\left(2 \mathrm{~A} 1_{g}+5 \mathrm{E}_{\mathrm{g}}\right)$ are expected in the Raman spectrum of $\alpha-\mathrm{Fe}_{2} \mathrm{O}_{3} \cdot{ }^{14}$ The peaks located at 225, 245, 292, 408, 495,610 and $1320 \mathrm{~cm}^{-1}$ correspond to the characteristic peaks of $\alpha-\mathrm{Fe}_{2} \mathrm{O}_{3}$. The two peaks at 225 and $495 \mathrm{~cm}^{-1}$ correspond to the $\mathrm{A}_{\mathrm{g}}$ mode whereas the peaks at $245,292,408$ and $610 \mathrm{~cm}^{-1}$ are attributed to the $\mathrm{E}_{\mathrm{g}}$ mode.$^{15}$ There has been considerable controversy regarding the origin of $1320 \mathrm{~cm}^{-1}$ peak. Martin et al. ${ }^{16}$ suggested that this mode originates from a secondary magnon-photon interaction whereas Massey et al., ${ }^{17}$ proposed a secondary phonon-photon interaction. Notably, there is no peak at $660 \mathrm{~cm}^{-1}$ which is typical of $\mathrm{Fe}_{3} \mathrm{O}_{4}$ (ref. 18) and no other peaks due to polymorphs of $\mathrm{Fe}(\mathrm{III})$ oxide or oxyhydroxides (such as $\gamma-\mathrm{Fe}_{2} \mathrm{O}_{3}, \alpha-\mathrm{FeOOH}$, and $\gamma-\mathrm{FeOOH}$ ) are found. This suggests the phase and compositional purity of $\alpha-\mathrm{Fe}_{2} \mathrm{O}_{3}$ prepared in the present study. Raman spectra were also recorded for $\alpha-\mathrm{Fe}_{2} \mathrm{O}_{3}$ film after Ir-Pi deposition. As it is seen in Fig. 3(iii), no additional peaks for Ir-Pi catalysts are found, and only the peaks corresponding to $\alpha-\mathrm{Fe}_{2} \mathrm{O}_{3}$ are present in the spectrum.

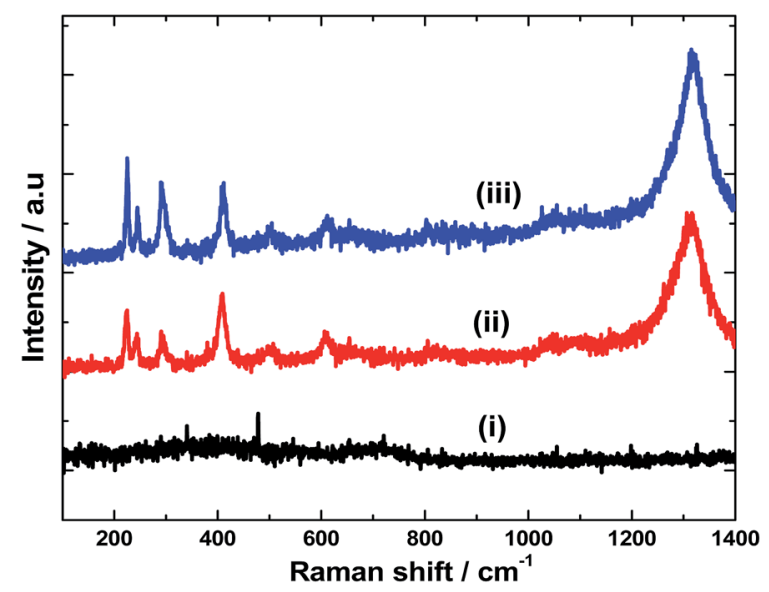

Fig. 3 Raman spectra of (i) $\mathrm{Fe}$, (ii) $\mathrm{Fe}_{2} \mathrm{O}_{3}$, and (iii) $\mathrm{Ir}-\mathrm{Pi}-\mathrm{Fe}_{2} \mathrm{O}_{3}$ on FTO substrates. Excitation wavelength: $532 \mathrm{~nm}$.

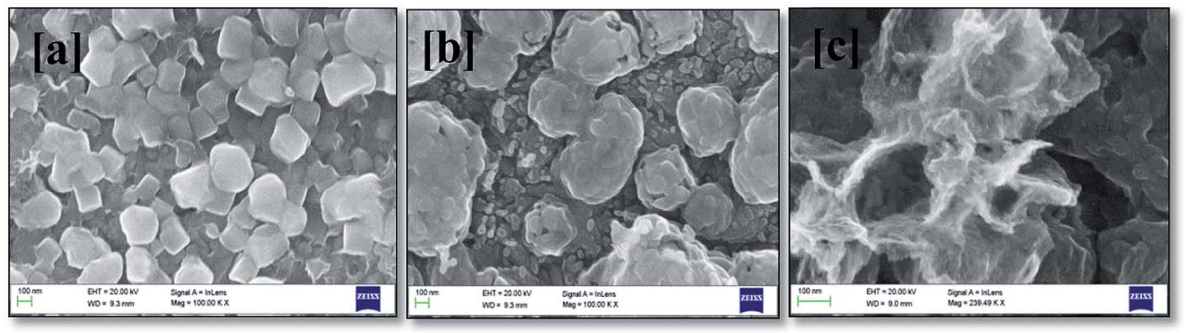

Fig. 2 SEM images of (a) $\mathrm{Fe}$, (b) $\mathrm{Fe}_{2} \mathrm{O}_{3}$, and (c) Ir-Pi- $-\mathrm{Fe}_{2} \mathrm{O}_{3}$ on FTO substrates. 
Moreover, there is no shift in the peaks positions after decorating with Ir-Pi catalyst.

\subsection{Chemical composition}

XRD and Raman studies confirm both electrodeposition of $\mathrm{Fe}$ film and its conversion to $\alpha-\mathrm{Fe}_{2} \mathrm{O}_{3}$ upon heating at $600{ }^{\circ} \mathrm{C}$ in air. Hence further physicochemical studies are mainly performed for detecting Ir and P after the electrochemical deposition of IrPi catalyst. Hence, EDXA and XPS measurements were carried out for $\mathrm{Fe}_{2} \mathrm{O}_{3}$ before and after Ir-Pi deposition. EDXA spectra are shown Fig. 4. In the case of $\mathrm{Fe}_{2} \mathrm{O}_{3}$ (Fig. 4a), major peaks are assigned to $\mathrm{Fe}, \mathrm{O}, \mathrm{Si}$ and $\mathrm{Sn}$. Presence of $\mathrm{Fe}$ and $\mathrm{O}$ indicate the formation of $\mathrm{Fe}_{2} \mathrm{O}_{3}$ whereas $\mathrm{Si}$ and $\mathrm{Sn}$ peaks are from the underlying FTO coated glass substrate. On the other hand, EDXA spectrum of $\mathrm{Fe}_{2} \mathrm{O}_{3}$ after the deposition of Ir-Pi (Fig. 4b), shows the presence of Ir and $\mathrm{P}$ along with peaks corresponding to $\mathrm{Fe}$ and $\mathrm{O}$. The atomic percentages of Ir, $\mathrm{P}$ and $\mathrm{Fe}$ are $2.5 \%$, $3.4 \%$ and $6.9 \%$, respectively. Thus, Ir-Pi has Ir and P in a ratio $1: 1.36$ which closely matches with the reported chemical composition of Ir-Pi on carbon. ${ }^{11}$ These studies confirm the formation of Ir-Pi catalyst during the anodic polarization of $\mathrm{Fe}_{2} \mathrm{O}_{3}$ electrodes in neutral phosphate buffer solution containing II $^{3+}$ ions.

X-ray photoelectron spectra were recorded for $\mathrm{Fe}_{2} \mathrm{O}_{3}$ after electrochemically depositing Ir-Pi and the results are shown in Fig. 5. In the Fe 2p region (Fig. 5a), a pair of peaks are present at 724.4 and $710.8 \mathrm{eV}$, which correspond to $\mathrm{Fe} 2 \mathrm{p}_{1 / 2}$ and $2 \mathrm{p}_{3 / 2}$, respectively. ${ }^{19} \mathrm{Fe} 2 \mathrm{p}_{3 / 2}$ peak appears to be narrower and stronger than $\mathrm{Fe} 2 \mathrm{p}_{1 / 2}$. Also, the area of $\mathrm{Fe} 2 \mathrm{p}_{3 / 2}$ peak is greater than that
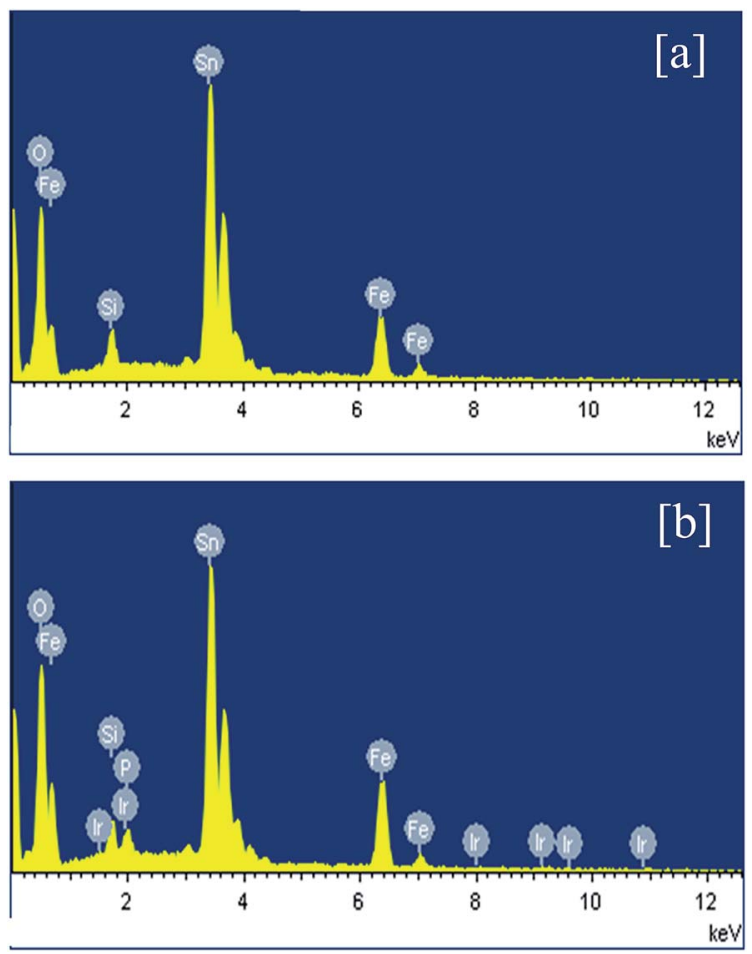

Fig. 4 EDXA spectra of (a) $\mathrm{Fe}_{2} \mathrm{O}_{3}$ and (b) $1 \mathrm{r}-\mathrm{Pi}-\mathrm{Fe}_{2} \mathrm{O}_{3}$ on $\mathrm{FTO}$ substrates. of Fe $2 p_{1 / 2}$ because Fe $2 p_{3 / 2}$ has degeneracy of four states while Fe $2 \mathrm{p}_{1 / 2}$ has only two, in spin-orbit coupling. ${ }^{20} \mathrm{~A}$ satellite peak of $\mathrm{Fe} 2 \mathrm{p}_{3 / 2}$ peak is found at $718.9 \mathrm{eV}$ which is $8.1 \mathrm{eV}$ higher than the binding energy of Fe $2 \mathrm{p}_{3 / 2}$ and this peak does not overlap with main photoelectron peaks. There is another peak at higher energy side of $\mathrm{Fe} 2 \mathrm{p}_{1 / 2}$, which may be a satellite peak for Fe $2 \mathrm{p}_{1 /}$ 2. In the Fe $2 p$ spectrum, no characteristic peaks for metallic Fe or other oxides of $\mathrm{Fe}$ are found. The results indicate that the $\mathrm{Fe}$ is in $\mathrm{Fe}^{3+}$ state and the oxide formed after heat treatment to $\mathrm{Fe}$ film is predominantly $\mathrm{Fe}_{2} \mathrm{O}_{3}$. In the high resolution spectrum of Ir $4 \mathrm{f}$ (Fig. 5b), a doublet is present at 62.2 and $65.2 \mathrm{eV}$, which correspond to $\mathrm{Ir} 4 \mathrm{f}_{7 / 2}$ and $4 \mathrm{f}_{5 / 2}$, respectively. ${ }^{21}$ The $4 \mathrm{f}_{5 / 2}$ peak is more intense than the $4 \mathrm{f}_{7 / 2}$ signal and the spin-orbit splitting value is $3.0 \mathrm{eV}$. These results are comparable to the literature values of Ir $4 \mathrm{f}$ in the Ir-Pi catalysts on carbon paper. ${ }^{11}$ The peak at $133.1 \mathrm{eV}$ in P 2p spectrum (Fig. 5c) is assigned to phosphate. ${ }^{22}$ This is similar to the binding energy of P $2 p$ in the Ir-Pi catalyst on carbon electrode, ${ }^{11}$ but the binding energy is marginally greater $(0.3 \mathrm{eV})$ than the $\mathrm{P} 2 \mathrm{p}$ peak observed in the case of Co-Pi deposited on carbon. ${ }^{23}$

\subsection{Bandgap measurements}

In order to study the optical properties, UV-VIS diffuse reflectance spectroscopy (DRS) measurements were carried out and the results are shown in Fig. 6a. The prepared $\alpha-\mathrm{Fe}_{2} \mathrm{O}_{3}$ displays strong light absorption capability both in UV and visible light region (Fig. 6a(i)). The absorption edge is around $567 \mathrm{~nm}$ which is close to the values reported in the literature. ${ }^{4-6}$ However, after depositing Ir-Pi on the surface of $\alpha-\mathrm{Fe}_{2} \mathrm{O}_{3}$, the absorption onset is blue shifted to $545 \mathrm{~nm}$ (Fig. 6a(ii)), indicating a modified band gap. Also, Ir-Pi deposited $\mathrm{Fe}_{2} \mathrm{O}_{3}$ shows higher reflectance than bare $\mathrm{Fe}_{2} \mathrm{O}_{3}$ between 450 and $750 \mathrm{~nm}$. To accurately find the band gaps of the materials, Tauc equation was used, ${ }^{24}$

$$
(\alpha h \nu)=A\left(h \nu-E_{\mathrm{g}}\right)^{n}
$$

where $\alpha$ is the absorption coefficient, $h \nu$ is photon energy, $A$ is a constant which does not depend on $h v$ and $E_{\mathrm{g}}$ is the band gap. Here, $n$ can take values of $3,2,3 / 2$ and $1 / 2$ corresponding to indirect (forbidden), indirect (allowed), direct (forbidden) and direct (allowed) transitions, respectively. ${ }^{25}$ Thus, the plots of $(\alpha h \nu)^{1 / n}$ versus $h \nu$ (Tauc plots) yield the value of the $E_{\mathrm{g}}$ when extrapolated to $(\alpha h \nu)^{1 / n}=0$. In the present case, $n=2$ is used to account for the indirect allowed optical transition in $\mathrm{Fe}_{2} \mathrm{O}_{3}$ and $\alpha$ values are extracted from the reflectance using Kubelka-Munk radiative transfer model. ${ }^{26}$ As it is seen from the inset of Fig. 6a, the Tauc plot provides the $E_{\mathrm{g}}$ of $2.18 \mathrm{eV}$ for bare $\mathrm{Fe}_{2} \mathrm{O}_{3}$ whereas it is slightly modified to $2.28 \mathrm{eV}$ after depositing Ir-Pi catalyst.

Flat band potential $\left(E_{\mathrm{FB}}\right)$ is an approximate measure of the conduction band position in n-type semiconductors. Moreover, it provides the theoretical onset potential $\left(E_{\text {onset }}\right)$ for the photoelectrochemical oxygen evolution reaction. In general, the flatband potential is determined by measuring the capacitance $(C)$ at different electrode potential $(E)$ using the following equation,

$$
1 / C^{2}=\left[2 / \varepsilon_{\mathrm{r}} \varepsilon_{0} e N_{\mathrm{d}}\right]\left[E-E_{\mathrm{FB}}-\left(k_{\mathrm{B}} T / e\right)\right]
$$



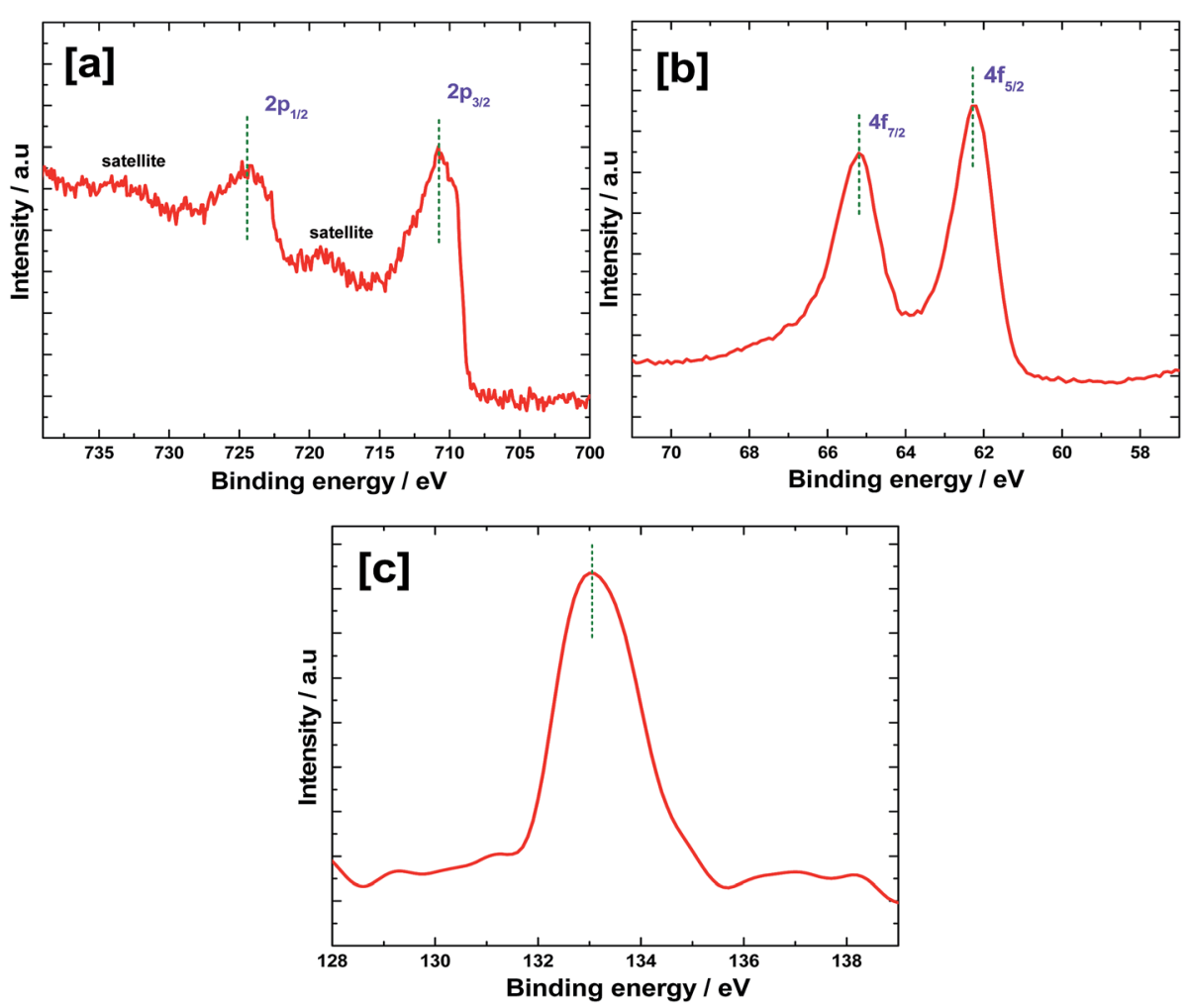

Fig. 5 XPS high resolution spectra of (a) Fe 2p, (b) Ir $4 f$ and (c) P $2 p$ of $I r-P i-\mathrm{Fe}_{2} \mathrm{O}_{3}$.

where $e$ is the electronic charge, $\varepsilon_{\mathrm{r}}$ is the dielectric constant of the semiconductor, $\varepsilon_{0}$ is the permittivity of air, $N_{\mathrm{d}}$ is the donor density, $E$ is the applied potential and $E_{\mathrm{FB}}$ is the flatband potential. Thus, $X$-intercept of the linear region of the MottSchottky plot $\left(1 / C^{2} v s . E\right)$ provides the $E_{\mathrm{FB}}$ of the semiconductor electrode. Accordingly, we examined the behavior of the bulk capacitance of $\mathrm{Fe}_{2} \mathrm{O}_{3}$ and Ir-Pi deposited $\mathrm{Fe}_{2} \mathrm{O}_{3}$ electrodes using electrochemical impedance spectroscopy at $10 \mathrm{kHz}$ in the potential range 0.60-1.1 V. The resulting Mott-Schottky plot is shown in Fig. 6b. In the case of $\alpha-\mathrm{Fe}_{2} \mathrm{O}_{3}$ electrode, $E_{\mathrm{FB}}$ value is about $0.59 \mathrm{~V}$ (Fig. 6b(i)). This is in agreement with literature reports on $E_{\mathrm{FB}}$ of $\alpha-\mathrm{Fe}_{2} \mathrm{O}_{3} \cdot{ }^{27}$ Similarly, Fig. $6 \mathrm{~b}(\mathrm{ii})$ shows the M-S plot of $\alpha-\mathrm{Fe}_{2} \mathrm{O}_{3}$ electrode after Ir-Pi deposition. Only a negligible change in $E_{\mathrm{FB}}$ to $0.61 \mathrm{~V}$ is noticed in the presence of Ir-Pi. Since $E_{\mathrm{FB}}$ is an approximate measure of conduction band position in n-type semiconductor, these studies rule out any drastic shift in the conduction band of $\mathrm{Fe}_{2} \mathrm{O}_{3}$ by Ir-Pi deposition.

\subsection{Optimization of Fe film}

The thickness of Fe film and thus $\mathrm{Fe}_{2} \mathrm{O}_{3}$ thickness needs to be optimized for achieving a high photoelectrochemical performance towards water oxidation reaction. For this, several electrodes were prepared by depositing Fe at $-1.05 \mathrm{~V} v s$. SCE for 1$15 \mathrm{~min}$. Electrodes were rinsed with water, dried in Ar flow and heated at $600{ }^{\circ} \mathrm{C}$ for $2 \mathrm{~h}$ in air to form $\alpha-\mathrm{Fe}_{2} \mathrm{O}_{3}$. PEC studies were carried out by linear sweep voltammetry at $50 \mathrm{mV} \mathrm{s}^{-1}$ in $0.1 \mathrm{M}$ neutral phosphate buffer solution under illumination from both front and back sides of the coating. The photocurrent density values so obtained at $1.23 \mathrm{~V}$ vs. RHE are plotted as a function of Fe deposition time in Fig. 7a. As it is seen from Fig. 7a(i), in the case of front side illumination, a photocurrent density as low as $18 \mu \mathrm{A} \mathrm{cm}^{-2}$ is obtained for $1 \mathrm{~min}$ of deposition. It increases to $23 \mu \mathrm{A} \mathrm{cm} \mathrm{cm}^{-2}$ for 2 min deposited $\mathrm{Fe}$ and reaches maximum of $62 \mu \mathrm{A} \mathrm{cm} \mathrm{cm}^{-2}$ for $5 \mathrm{~min}$. Further increase in the deposition time has negative effect and photocurrent falls to 56 $\mu \mathrm{A} \mathrm{cm}^{-2}$ for $7 \mathrm{~min}$. It further decreases to 36 and $18 \mu \mathrm{A} \mathrm{cm}^{-2}$ for 10 and 15 min deposited films, respectively. Similar trend is also observed for back side illuminated electrodes, however with much lower values of photocurrent (Fig. 7a(ii)). In this case, photocurrent density values of $12,21,25,23,20$ and $6 \mu \mathrm{A}$ $\mathrm{cm}^{-2}$ are obtained for Fe deposition of 1, 2, 5, 7, 10 and $20 \mathrm{~min}$, respectively. Thus, the highest photoresponse is observed for 5 min deposited electrodes in both the cases. The highest photocurrent density values are 62 and $25 \mu \mathrm{A} \mathrm{cm}{ }^{-2}$, respectively for front and back side illuminated electrodes. The low photoresponse in the case of back side illuminated electrodes could be due to light absorption and scattering by the glass substrate.

It is also important to optimize the calcination temperature to get high photoresponse. Very low heating temperature will result in poor crystallinity and very high temperature can cause the degradation of FTO substrate and subsequent loss in conductivity. In order to perform the temperature optimization, several Fe electrodes were prepared by depositing at $-1.05 \mathrm{~V}$ for $5 \mathrm{~min}$. Then, they were heated at different temperatures in the range of $400-800{ }^{\circ} \mathrm{C}$ for $2 \mathrm{~h}$ in air, and PEC measurements were carried out as in above case. A plot of photocurrent density at $1.23 \mathrm{~V} v s$. RHE against calcination temperature is shown in 

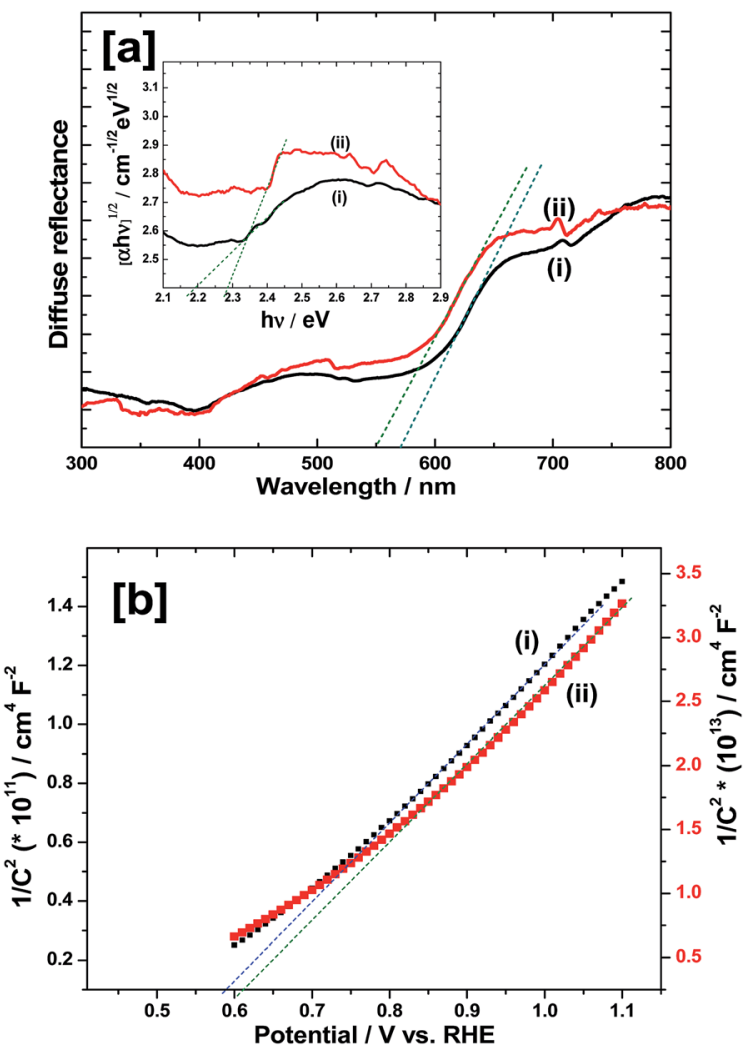

Fig. 6 (a) DRS spectra of (i) $\mathrm{Fe}_{2} \mathrm{O}_{3}$ and (ii) $\mathrm{Ir}-\mathrm{Pi}-\mathrm{Fe}_{2} \mathrm{O}_{3}$ on FTO substrates. Inset shows corresponding Tauc plots near the band gap. (b) Mott-Schottky plots at $10 \mathrm{kHz}$ for (i) $\mathrm{Fe}_{2} \mathrm{O}_{3}$ and (ii) $\mathrm{Ir}-\mathrm{Pi}-\mathrm{Fe}_{2} \mathrm{O}_{3}$ in $0.1 \mathrm{M}$ phosphate electrolytes of $\mathrm{pH}$ 7.0. Ir-Pi was deposited at $1.0 \mathrm{~V}$ vs. SCE for $25 \mathrm{~min}$ from $0.5 \mathrm{mM} \mathrm{IrCl}_{3}+0.1 \mathrm{M}$ neutral phosphate solution.

Fig. 7b. Results are obtained for both front side (Fig. 7b(i)) and back side (Fig. $7 \mathrm{~b}(\mathrm{ii})$ ) illuminations. In the case of front side illumination (Fig. $7 \mathrm{~b}(\mathrm{i})$ ), a low photocurrent density value of $8 \mu \mathrm{A}$ $\mathrm{cm}^{-2}$ is obtained when the calcination temperature is $400{ }^{\circ} \mathrm{C}$. Such a poor performance could be due to incomplete conversion of $\mathrm{Fe}$ to photoactive $\mathrm{Fe}_{2} \mathrm{O}_{3}$ and also due to poor crystallinity of $\mathrm{Fe}_{2} \mathrm{O}_{3}$ so formed at this temperature. However, on heating at $500{ }^{\circ} \mathrm{C}$, the photocurrent $\left(33 \mu \mathrm{A} \mathrm{cm}{ }^{-2}\right)$ is enhanced by nearly 4 times. Highest photocurrent is seen for $\mathrm{Fe}_{2} \mathrm{O}_{3}$ heated at $600{ }^{\circ} \mathrm{C}$ and the photocurrent density is $62 \mu \mathrm{A} \mathrm{cm}^{-2}$. On further heating to $700{ }^{\circ} \mathrm{C}$, current falls to $46 \mu \mathrm{A} \mathrm{cm}^{-2}$ which again drops to $26 \mu \mathrm{A}$ $\mathrm{cm}^{-2}$ at $800{ }^{\circ} \mathrm{C}$. Similar trend is observed for back side illuminated electrodes (Fig. $7 \mathrm{~b}(\mathrm{ii})$ ). Photocurrent of $6 \mu \mathrm{A} \mathrm{cm} \mathrm{cm}^{-2}$ for $400{ }^{\circ} \mathrm{C}$ sample is increased to $21 \mu \mathrm{A} \mathrm{cm}^{-2}$ at $500{ }^{\circ} \mathrm{C}$. Maximum activity of $24 \mu \mathrm{A} \mathrm{cm}{ }^{-2}$ is obtained for $600{ }^{\circ} \mathrm{C}$ and on further raising the temperature to $700{ }^{\circ} \mathrm{C}$, current falls to $20 \mu \mathrm{A} \mathrm{cm}{ }^{-2}$. It again reduces to $14 \mu \mathrm{A} \mathrm{cm}^{-2}$ for $800^{\circ} \mathrm{C}$ sample. Overall, there are two observations. First one is that, both in front side and back side illuminations, maximum photoactivity is obtained for $\mathrm{Fe}$ films heated at $600{ }^{\circ} \mathrm{C}$. Secondly, the photocurrent observed for front side illumination is much higher than that for back side illuminated electrodes. For instance, for 5 min deposited and $600{ }^{\circ} \mathrm{C}$ heated films, a photocurrent density value of $62 \mu \mathrm{A} \mathrm{cm}{ }^{-2}$ is obtained during the front side illumination whereas it is only $24 \mu \mathrm{A} \mathrm{cm}^{-2}$ for the back side illumination.
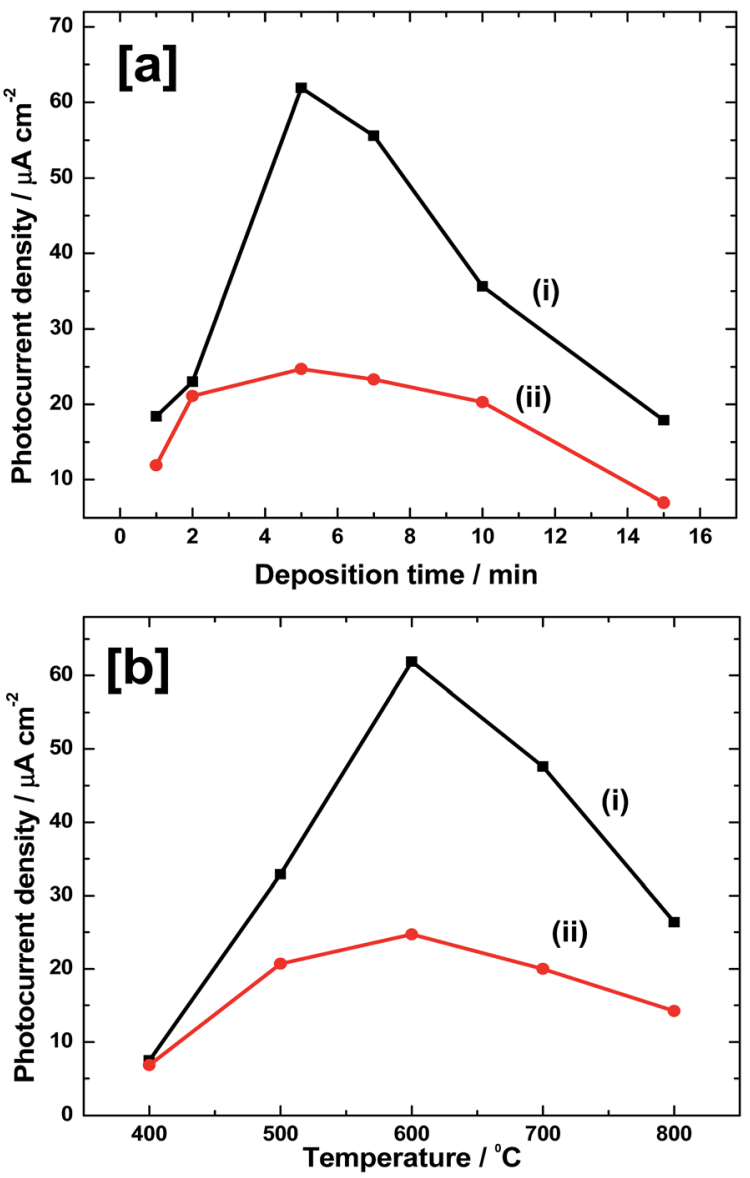

Fig. 7 (a) Photocurrent density values at $1.23 \mathrm{~V}$ vs. RHE during LSV experiments in $0.1 \mathrm{M}$ phosphate electrolytes of $\mathrm{pH} 7.0$ for (i) front side and (ii) back side illuminations against Fe deposition time. All electrodes were heated at $600{ }^{\circ} \mathrm{C}$ for $2 \mathrm{~h}$ in air. (b) Photocurrent density values at $1.23 \mathrm{~V}$ vs. RHE during LSV experiments in $0.1 \mathrm{M}$ phosphate electrolytes of $\mathrm{pH} 7.0$ for (i) front side and (ii) back side illuminations, against the calcination temperatures. All electrodes were deposited at $-1.05 \mathrm{~V}$ for $5 \mathrm{~min}$ from $10 \mathrm{mM} \mathrm{FeSO}_{4}$ solution. Electrodes were heated for $2 \mathrm{~h}$ in air at a temperature.

\subsection{Electrodeposition of Ir-Pi on $\alpha-\mathrm{Fe}_{2} \mathrm{O}_{3}$}

In order to confirm the electrochemical deposition of Ir-Pi on $\alpha$ $\mathrm{Fe}_{2} \mathrm{O}_{3}$ substrate, cyclic voltammetry experiments were carried out. Cyclic voltammograms of $\alpha-\mathrm{Fe}_{2} \mathrm{O}_{3}$ coated FTO in $0.1 \mathrm{M}$ phosphate buffer solution ( $\mathrm{pH} 7.0$ ) containing $0.5 \mathrm{mM} \mathrm{IrCl}_{3}$ are shown in Fig. 8. After completing the first cycle (Fig. 8(i)), a broad oxidation peak centered at around $0.50 \mathrm{~V} v s$. SCE is seen. This broad peak region almost covers the observed potentials for $\mathrm{Ir}^{3+/ 4+}$ and $\mathrm{Ir}^{4+/ 5+}$ transitions during the deposition of Ir-Pi on carbon paper electrode. ${ }^{11}$ Hence, it is anticipated that the broad peak in the present study is due to the overlapping of two oxidation peaks, and oxidation state of Ir is +5 after completing a half cycle. During the negative scan (Fig. 8(i)), a weak and broad reduction peak at $0.40 \mathrm{~V} v s$. SCE can be seen. To study the growth process of Ir-Pi, potential cycling was repeated. The cyclic voltammogram after completing the $10^{\text {th }}$ cycle is shown in Fig. 8(ii), which resembles the features of first cycle voltammogram (Fig. 8(i)), but with a large increase in the 


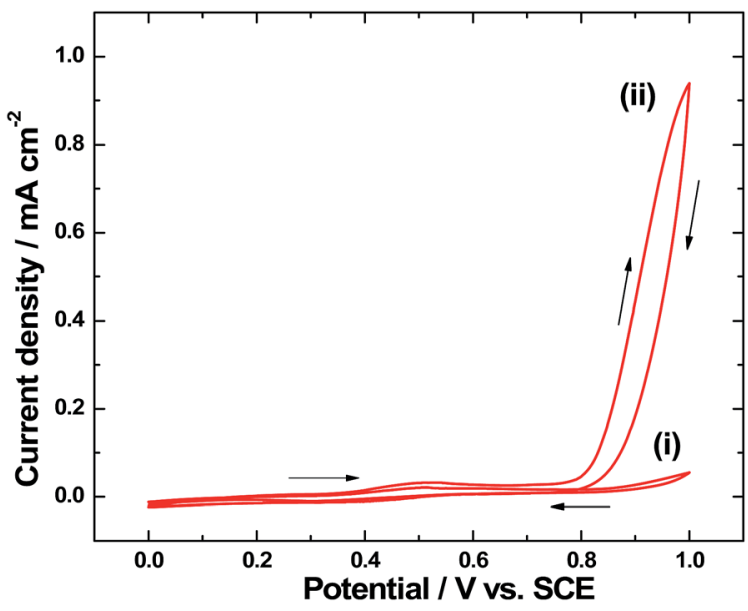

Fig. 8 Cyclic voltammograms of $\alpha-\mathrm{Fe}_{2} \mathrm{O}_{3}-\mathrm{FTO}$ electrode in $0.1 \mathrm{M}$ neutral phosphate solution containing $0.5 \mathrm{mM} \mathrm{IrCl}_{3}$ after completing (i) first cycle and (ii) $10^{\text {th }}$ cycle at $5 \mathrm{mV} \mathrm{s}^{-1}$.

current above $0.80 \mathrm{~V} v s$. SCE. This is attributed to the electrochemical oxidation of water on thick Ir-Pi catalyst grown on the surface of $\alpha-\mathrm{Fe}_{2} \mathrm{O}_{3}$. These studies suggest that Ir-Pi catalyst deposition can be done on $\alpha-\mathrm{Fe}_{2} \mathrm{O}_{3}$ above $0.60 \mathrm{~V}$ vs. SCE at a reasonable rate from $0.5 \mathrm{mM} \mathrm{Ir}^{3+}$ solutions.

\subsection{Effect of Ir-Pi deposition on PEC activity}

To study the effect of Ir-Pi deposition on $\alpha-\mathrm{Fe}_{2} \mathrm{O}_{3}$ for oxygen evolution reaction (OER) under photoelectrochemical condition, Ir-Pi was deposited onto $\alpha-\mathrm{Fe}_{2} \mathrm{O}_{3}$ electrode from $0.5 \mathrm{mM}$ $\mathrm{IrCl}_{3}+0.1 \mathrm{M}$ phosphate solution ( $\mathrm{pH} 7.0$ ) at $1.0 \mathrm{~V}$ vs. SCE for $25 \mathrm{~min}$. Then, the linear sweep voltammograms were recorded for both $\mathrm{Fe}_{2} \mathrm{O}_{3}$ and Ir-Pi- $\mathrm{Fe}_{2} \mathrm{O}_{3}$ at $50 \mathrm{mV} \mathrm{s}{ }^{-1}$ in $0.1 \mathrm{M}$ neutral phosphate electrolyte under front side illuminations. Results are shown in Fig. 9a. In the case of bare $\mathrm{Fe}_{2} \mathrm{O}_{3}$, only negligibly small current flows in dark till potential reaches $1.80 \mathrm{~V}$, indicating the absence of any electrochemical reaction at this potential range. However, current increases sharply above 1.80 V due to electrochemical OER (Fig. 9a(i)). Upon illumination of $\mathrm{Fe}_{2} \mathrm{O}_{3}$ electrode, current starts flowing at potential close to $1.0 \mathrm{~V}$ and it reaches $62 \mu \mathrm{A} \mathrm{cm} \mathrm{cm}^{-2}$ at $1.23 \mathrm{~V}$ (Fig. 9a(ii)). The photocurrent onset is around $400 \mathrm{mV}$ higher than the experimentally determined flatband potential of $\mathrm{Fe}_{2} \mathrm{O}_{3}$, suggesting a high overpotential for PEC oxygen evolution on as-prepared $\mathrm{Fe}_{2} \mathrm{O}_{3}$ electrode. On the other hand, the onset potential is as low as $0.65 \mathrm{~V}$ in the case of $\mathrm{Ir}-\mathrm{Pi}-\mathrm{Fe}_{2} \mathrm{O}_{3}$ (Fig. 9a(iv)), which is $350 \mathrm{mV}$ lower than that on bare $\mathrm{Fe}_{2} \mathrm{O}_{3}$ electrode under identical conditions. Similar to the present study, $\mathrm{IrO}_{2}$ nanoparticles loaded $\mathrm{Fe}_{2} \mathrm{O}_{3}$ was reported for photoelectrochemical water oxidation. ${ }^{28}$ Around $200 \mathrm{mV}$ cathodic shift in the photocurrent onset was observed after $\mathrm{IrO}_{2}$ deposition. Similarly, photoelectrodeposited Co-Pi caused $170 \mathrm{mV}$ improvement ${ }^{29}$ whereas FeOOH cocatalyst shifted the onset potential by $120 \mathrm{mV} .{ }^{30}$ It is also reported that photo or electrochemical deposition of $\mathrm{Ni}$ oxides or Co-oxides on hematite could lower the required bias voltage by $100-300 \mathrm{mV} .^{31}$ Thus, $350 \mathrm{mV}$ cathodic shift in OER
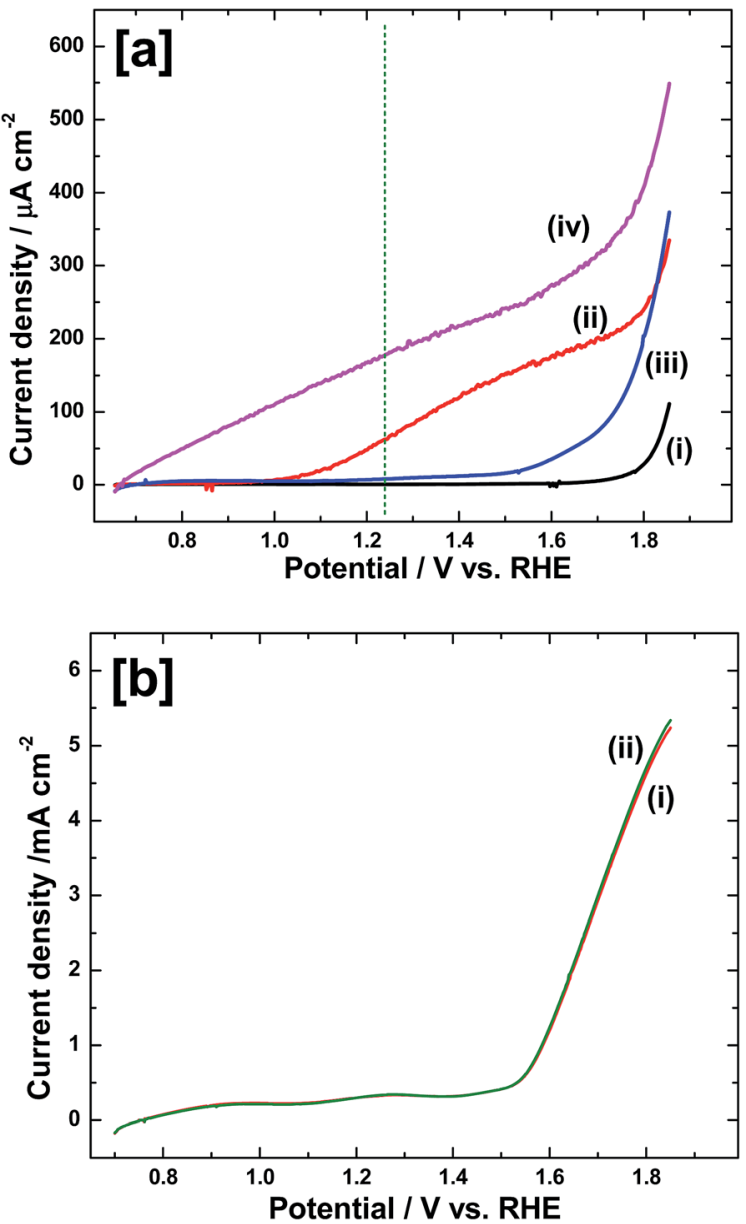

Fig. 9 (a) Linear sweep voltammograms of bare $\mathrm{Fe}_{2} \mathrm{O}_{3}$ in (i) dark and (ii) light, and of $\mathrm{Ir}-\mathrm{Pi}-\mathrm{Fe}_{2} \mathrm{O}_{3}$ under (iii) dark and (iv) light in $0.1 \mathrm{M}$ neutral phosphate solution. Ir-Pi was deposited at $1.0 \mathrm{~V}$ vs. SCE for $25 \mathrm{~min}$ from $0.5 \mathrm{mM} \mathrm{Ir}^{3+}+0.1 \mathrm{M}$ phosphate $(\mathrm{pH} 7.0)$ electrolyte. (b) Linear sweep voltammograms of electrodeposited Ir-Pi on FTO glass in $0.1 \mathrm{M}$ phosphate solution ( $\mathrm{pH}$ 7.0) under (i) dark and (ii) illumination conditions. For this study, Ir-Pi was deposited at $1.1 \mathrm{~V} v$ s. SCE for $2 \mathrm{~h}$ from $0.5 \mathrm{mM} \mathrm{Ir}^{3+}+0.1 \mathrm{M}$ phosphate $(\mathrm{pH} 7.0)$ solution. In all the cases, sweep rate was $50 \mathrm{mV} \mathrm{s}^{-1}$ and illumination was done through the front side.

onset potential observed for Ir-Pi deposited $\mathrm{Fe}_{2} \mathrm{O}_{3}$ in the present case is superior to the literature reports on similar studies using $\mathrm{Co}-\mathrm{Pi}, \mathrm{IrO}_{2}, \mathrm{FeOOH}$ and $\mathrm{Co} / \mathrm{Ni}$-oxide catalysts. In addition, a high current density of $180 \mu \mathrm{A} \mathrm{cm}^{-2}$ is observed at $1.23 \mathrm{~V}$ for Ir-Pi loaded $\mathrm{Fe}_{2} \mathrm{O}_{3}$ which is 2.9 times higher than the current observed for $\mathrm{Fe}_{2} \mathrm{O}_{3}$ electrode alone. Under dark also, onset potential of electrochemical OER is reduced to $1.50 \mathrm{~V}$ on Ir-Pi$\mathrm{Fe}_{2} \mathrm{O}_{3}$ from $1.80 \mathrm{~V}$ observed for $\mathrm{Fe}_{2} \mathrm{O}_{3}$ without Ir-Pi (Fig. 9a(i) and (iii)). This is anticipated owing to high electrochemical activity of Ir-Pi catalyst towards electrochemical OER. Also, applied bias photon-to-current efficiency (ABPE) calculated from LSV curve indicates a maximum value of $0.027 \%$ at $0.90 \mathrm{~V}$ for Ir-Pi- $\mathrm{Fe}_{2} \mathrm{O}_{3}$ whereas it is 10 times less $(0.0027 \%)$ for bare $\mathrm{Fe}_{2} \mathrm{O}_{3}$ at $1.10 \mathrm{~V}$ (Fig. $\mathrm{S} 3 \dagger$ ). The evolved gas was detected and confirmed as oxygen using Pt electrode sensor (Fig. S4†). These results clearly confirm the electrochemical deposition of Ir-Pi and its positive role towards both electrochemical and 
photoelectrochemical OER in neutral electrolytes. To rule out the possibility that Ir-Pi itself is photoactive along with $\mathrm{Fe}_{2} \mathrm{O}_{3}$ electrode, Ir-Pi was deposited on FTO glass and then, the linear sweep voltammograms were recorded in phosphate solution under dark (Fig. 9b(i)) and light (Fig. 9b(ii)) conditions. It is seen from Fig. $9 \mathrm{~b}$ that there is no enhancement in the current upon illuminating the Ir-Pi-FTO electrode. This suggests that Ir$\mathrm{Pi}$ alone is inactive towards photooxidation of water, and it merely acts as a cocatalyst for the reaction on $\mathrm{Fe}_{2} \mathrm{O}_{3}$ photoelectrode. It is also noted that the incident photon-to-current efficiency (IPCE) at $1.50 \mathrm{~V}$ vs. RHE is increased by 1.5 times after interfacing with Ir-Pi catalyst (Fig. S5†).

\subsection{Optimization of Ir-Pi thickness}

It is necessary to optimize the loading level of Ir-Pi on $\alpha-\mathrm{Fe}_{2} \mathrm{O}_{3}$ to achieve maximum photoresponse. For this, Ir-Pi was deposited from $0.5 \mathrm{mM} \mathrm{IrCl}_{3}+0.1 \mathrm{M}$ phosphate solution ( $\mathrm{pH} 7.0$ ) at $1.0 \mathrm{~V}$ vs. SCE for different time intervals in the range of 0 to $40 \mathrm{~min}$. PEC water oxidation was studied by linear sweep voltammetry at $50 \mathrm{mV} \mathrm{s}^{-1}$ in $0.1 \mathrm{M}$ neutral phosphate electrolyte both by front side and back side illuminations. The photocurrent density so obtained (after subtracting the dark current) in LSV at $1.23 \mathrm{~V}$ is plotted as the function of Ir-Pi deposition time in Fig. 10. As it is seen from Fig. 10(i), the current value for bare $\alpha-\mathrm{Fe}_{2} \mathrm{O}_{3}$ is $62 \mu \mathrm{A}$ $\mathrm{cm}^{-2}$ which increases to $66,78,97,139$ and $180 \mu \mathrm{A} \mathrm{cm}{ }^{-2}$ for 5 , 10, 15, 20 and 25 min Ir-Pi deposited electrodes. However, upon further increasing the deposition time to 30,35 and $40 \mathrm{~min}$, photocurrent falls to 106,65 and $20 \mu \mathrm{A} \mathrm{cm}^{-2}$, respectively. This could be due to partial scattering and absorption of incident light by thick layer of Ir-Pi catalyst on the surface of $\alpha-\mathrm{Fe}_{2} \mathrm{O}_{3}$. Thus, the maximum photoresponse is obtained for $25 \mathrm{~min}$ of IrPi deposition and the resultant photocurrent at $1.23 \mathrm{~V} v s$. RHE is 2.9 times higher than that of bare $\alpha-\mathrm{Fe}_{2} \mathrm{O}_{3}$. This indicates the favorable role of Ir-Pi as a cocatalyst for solar water oxidation

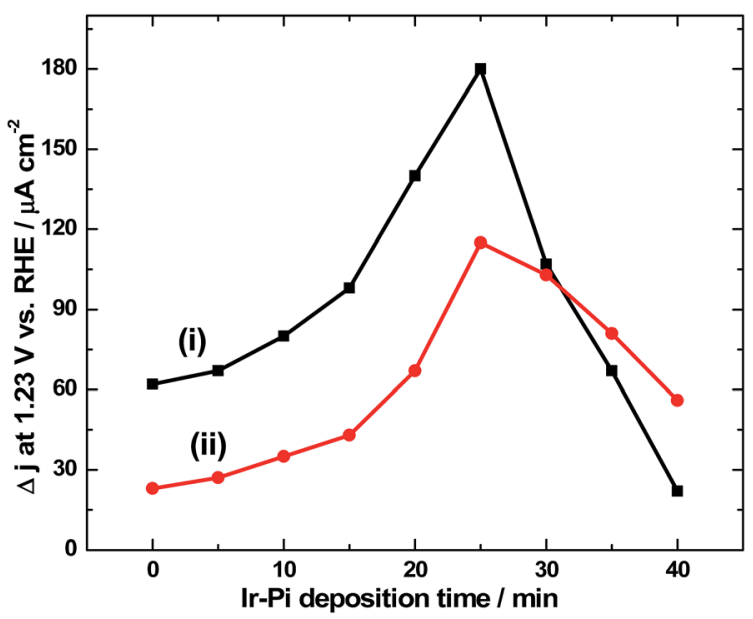

Fig. 10 Photocurrent density values at $1.23 \mathrm{~V}$ vs. RHE during LSV experiments in $0.1 \mathrm{M}$ phosphate electrolyte of $\mathrm{pH} 7.0$ for (i) front side and (ii) back side illuminations, against Ir-Pi deposition time. Ir-Pi was deposited at $1.0 \mathrm{~V}$ vs. SCE from $0.5 \mathrm{mM} \mathrm{IrCl}_{3}$ in $0.1 \mathrm{M}$ phosphate solution ( $\mathrm{pH}$ 7.0). $\alpha-\mathrm{Fe}_{2} \mathrm{O}_{3}$ was prepared under the optimized conditions. reaction. Similar studies were repeated in the case of back side illumination (Fig. 10(ii)). Here, the photocurrent density of 24 $\mu \mathrm{A} \mathrm{cm}{ }^{-2}$ for $\alpha-\mathrm{Fe}_{2} \mathrm{O}_{3}$ is increased to $27,35,41,67$ and $115 \mu \mathrm{A}$ $\mathrm{cm}^{-2}$, respectively for 5, 10, 15, 20 and 25 min Ir-Pi deposited electrodes. As in the case of front side illumination, deposition over 25 min causes a decrease in photocurrent. Current values of 102,80 and $55 \mu \mathrm{A} \mathrm{cm}^{-2}$ are obtained after 30,35 and $40 \mathrm{~min}$ of Ir-Pi deposition. It is worth noticing that, for the deposition time below $30 \mathrm{~min}$, front side illuminated electrodes show higher photocurrent than back side illuminations whereas at higher thickness, back side illuminated electrodes dominate. This is due to the fact that the light absorption by thick Ir-Pi layer is minimum during back side is illumination.

\subsection{Proposed mechanism}

Bandgap measurements using diffuse reflectance spectroscopy suggest only a slight shift in the $E_{\mathrm{g}}$ of $\mathrm{Fe}_{2} \mathrm{O}_{3}$ after Ir-Pi loading (Fig. 6a). Similarly, Mott-Schottky plots indicate almost no variation in the conduction band position of Ir-Pi- $\mathrm{Fe}_{2} \mathrm{O}_{3}$ compared to $\mathrm{Fe}_{2} \mathrm{O}_{3}$ (Fig. 6b). These studies clearly exclude any modification in the optical properties of $\mathrm{Fe}_{2} \mathrm{O}_{3}$ by Ir-Pi as a reason for the enhancement in PEC performance. Hence, it is proposed that the Ir-Pi deposit acts as a cocatalyst, and the enhancement in photocurrent is due to fast kinetics of OER at $\mathrm{Ir}-\mathrm{Pi}-\mathrm{Fe}_{2} \mathrm{O}_{3}$ electrode. A similar behavior was also reported for $\mathrm{Ir}^{32}$ and $\mathrm{CO}^{33}$ based catalysts deposited hematite photoanodes. The proposed mechanism of water oxidation reaction on Ir-Pi$\mathrm{Fe}_{2} \mathrm{O}_{3}$ hybrid photoelectrode is illustrated in scheme 1. In general, illumination of $\mathrm{Fe}_{2} \mathrm{O}_{3}$ produces electron-hole pairs. Electrons in the conduction band are transported to external circuit under applied bias. Although, the photogenerated holes in the valence bad of $\mathrm{Fe}_{2} \mathrm{O}_{3}$ can directly oxidize water, bare $\mathrm{Fe}_{2} \mathrm{O}_{3}$ has poor catalytic activity towards OER. Hence, in the absence Ir-Pi, most of the holes recombine with electrons without causing any reaction. Instead, in the presence Ir-Pi, $\operatorname{Ir}(\mathrm{IV} / \mathrm{v})$ centers in the catalyst layer rapidly accept the holes before recombining with electrons to form $\operatorname{Ir}(\mathrm{v} / \mathrm{vr})$ unit and thus the charge carrier separation is improved. Thermodynamically, the oxidation potential of $\operatorname{Ir}(\mathrm{v} / \mathrm{vr})$ is higher enough for the oxidation of water. Therefore, a high photocurrent due to an immediate evolution of oxygen gas is observed for Ir-Pi- $\mathrm{Fe}_{2} \mathrm{O}_{3}$. It

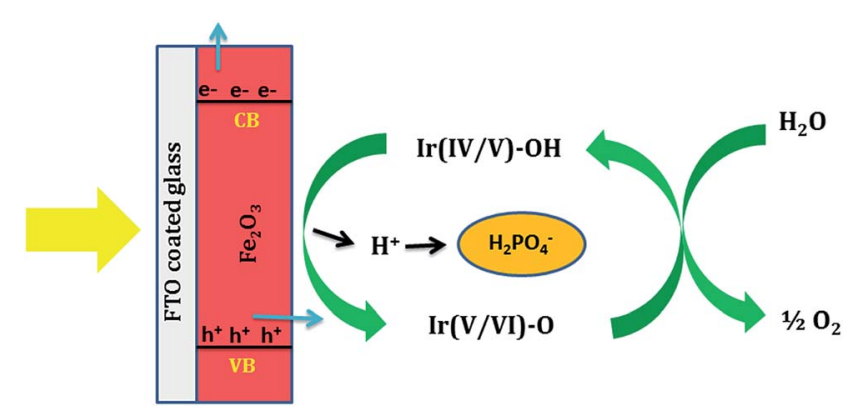

Scheme 1 Schematic illustration for the proposed mechanism of oxygen evolution reaction (OER) on $\mathrm{Ir}-\mathrm{Pi}$ deposited $\mathrm{Fe}_{2} \mathrm{O}_{3}$ photoelectrode. 
is proposed in the OER mechanism on Co-Pi that the catalyst undergoes a reversible one electron, one proton equilibrium step prior to a rate limiting oxygen evolution step. ${ }^{34}$ In the present case, the equilibrium redox process corresponds to the oxidation of $\operatorname{Ir}(\mathrm{Iv} / \mathrm{v})$ mixed valence cluster to $\operatorname{Ir}(\mathrm{v} / \mathrm{vI})$ unit along with liberation of $\mathrm{a} \mathrm{H}^{+}$,

$$
\operatorname{Ir}(\mathrm{IV} / \mathrm{v})-\mathrm{OH} \leftrightharpoons \operatorname{Ir}(\mathrm{v} / \mathrm{vI})-\mathrm{O}+\mathrm{H}^{+}+\mathrm{e}^{-}
$$

Phosphate ions in the electrolyte serve as the proton acceptor. Near neutral $\mathrm{pH}, \mathrm{HPO}_{4}{ }^{2-}$ is the most efficient proton acceptor although $\mathrm{H}_{2} \mathrm{PO}_{4}{ }^{-}$is also proposed to be a kinetically competent proton acceptor in this proton coupled electron transfer (PCET) process. ${ }^{34}$ Thus, phosphate plays a key role in maintaining this equilibrium. It is likely that the $\operatorname{Ir}(\mathrm{v} / \mathrm{vI})-\mathrm{O}$ so formed participates in an irreversible chemical reaction with $\mathrm{H}_{2} \mathrm{O}$ molecules leading to the evolution of $\mathrm{O}_{2}$ molecules from the surface of photoelectrode.

\section{Conclusions}

Photoelectrochemical water oxidation in neutral phosphate electrolyte was studied using $\alpha-\mathrm{Fe}_{2} \mathrm{O}_{3}$ as a photoanode and Ir-Pi as a cocatalyst. Electrochemical deposition of Fe film by the reduction of $\mathrm{Fe}^{2+}$ ions and its subsequent calcination above $400{ }^{\circ} \mathrm{C}$ in air resulted in the formation $\alpha-\mathrm{Fe}_{2} \mathrm{O}_{3}$ film. Under the optimized conditions, the as-prepared $\alpha-\mathrm{Fe}_{2} \mathrm{O}_{3}$ provided $62 \mu \mathrm{A}$ $\mathrm{cm}^{-2}$ for front side illumination and $24 \mu \mathrm{A} \mathrm{cm} \mathrm{cm}^{-2}$ for back side illumination, at $1.23 \mathrm{~V}$ vs. RHE in $0.1 \mathrm{M}$ neutral phosphate solution. After $25 \mathrm{~min}$ of Ir-Pi deposition at $1.0 \mathrm{~V} v$ s. SCE from $0.5 \mathrm{mM} \mathrm{IrCl}_{3}+0.1 \mathrm{M}$ phosphate solution ( $\mathrm{pH} 7.0$ ), there was an increase in the photocurrent density at $1.23 \mathrm{~V} v s$. RHE by 2.9 and 4.8 times, respectively for front and back side illuminated electrodes. The results of these studies indicate the favorable role of Ir-Pi as a cocatalyst for solar assisted water oxidation process in neutral solutions.

\section{Acknowledgements}

The authors thank CSIR, India for the financial support and CeNSe at IISc, Bangalore for the instrumental facilities. Special thanks to Ms Krishna for the technical assistance during IPCE measurement.

\section{References}

1 X. Li, J. Yu, J. Low, Y. Fang, J. Xiao and X. Chen, J. Mater. Chem. A, 2015, 3, 2485-2534.

2 M. G. Walter, E. L. Warren, J. R. McKone, S. W. Boettcher, Q. Mi, E. A. Santori and N. S. Lewis, Chem. Rev., 2010, 110, 6446-6473.

3 J. Gan, X. Lu and Y. Tong, Nanoscale, 2014, 6, 7142-7164.

4 T. W. Hamann, Dalton Trans., 2012, 41, 7830-7834.

5 P. S. Bassi, Gurudayal, L. H. Wong and J. Barber, Phys. Chem. Chem. Phys., 2014, 16, 11834-11842.

6 O. Zandi and T. W. Hamann, Phys. Chem. Chem. Phys., 2015, 17, 22485-22503.
7 D. K. Bora, A. Braun and E. C. Constable, Energy Environ. Sci., 2013, 6, 407-425.

8 J. J. Wang, Y. Hu, R. Toth, G. Fortunatoc and A. Braun, J. Mater. Chem. A, 2016, 4, 2821-2825.

9 B. Iandolo, B. Wickman, I. Zoric and A. Hellman, J. Mater. Chem. A, 2015, 3, 16896-16912.

10 J. Yang, D. Wang, H. Han and C. Li, Acc. Chem. Res., 2013, 46, 1900-1909.

11 A. Irshad and N. Munichandraiah, ACS Appl. Mater. Interfaces, 2015, 7, 15765-15776.

12 G. Rahman and O. S. Joo, Mater. Chem. Phys., 2013, 140, 316322.

13 T. K. Townsend, E. M. Sabio, N. D. Browning and F. E. Osterloh, Energy Environ. Sci., 2011, 4, 4270-4275.

14 D. Bersani, P. P. Lottici and A. Montenero, J. Raman Spectrosc., 1999, 30, 355-360.

15 Q. Wei, Z. Zhang, Z. Li, Q. Zhou and Y. Zhu, J. Phys. D: Appl. Phys., 2008, 41, 202002.

16 T. P. Martin, R. Merlin, D. R. Huffman and M. Cardona, Solid State Commun., 1977, 22, 565-567.

17 M. J. Massey, U. Baier, R. Merlin and W. H. Weber, Phys. Rev. $B, 1990,41,7822-7827$.

18 P. Kumar, P. Sharma, R. Shrivastav, S. Dass and V. R. Satsangi, Int. J. Hydrogen Energy, 2011, 36, 2777-2784.

19 F. Zhang, X. Li, Q. Zhao, Q. Zhang, M. Tade and S. Liu, J. Colloid Interface Sci., 2015, 457, 18-26.

20 G. Rahman and O. S. Joo, Int. J. Hydrogen Energy, 2012, 37, 13989-13997.

21 A. Korotcov, Y. S. Huang, D. S. Tsai and K. K. Tiong, J. Phys.: Condens. Matter, 2006, 18, 1121-1136.

22 S. Cobo, J. Heidkamp, P. A. Jacques, J. Fize, V. Fourmond, L. Guetaz, B. Jousselme, V. Ivanova, H. Dau, S. Palacin, M. Fontecave and V. Artero, Nat. Mater., 2012, 11, 802-807.

23 A. Irshad and N. Munichandraiah, Phys. Chem. Chem. Phys., 2014, 16, 5412-5422.

24 E. B. Ledesmaa, M. L. G. Benjumea, I. E. Cabrerab, M. O. Gutierrezc, F. J. E. Beltrand, J. Mostaghimie and M. E. C. Garcia, Mater. Sci. Eng., B, 2010, 174, 71-73.

25 R. Dholam, N. Patel, A. Santini and A. Miotello, Int. J. Hydrogen Energy, 2010, 35, 9581-9590.

26 P. Kubelka, J. Opt. Soc. Am., 1948, 38, 449-457.

27 A. Hankin, J. C. Alexander and G. H. Kelsall, Phys. Chem. Chem. Phys., 2014, 16, 16176-16186.

28 S. D. Tilley, M. Cornuz, K. Sivula and M. Gratzel, Angew. Chem., Int. Ed., 2010, 49, 6405-6408.

29 D. K. Zhong, M. Cornuz, K. Sivula, M. Gratzel and D. R. Gamelin, Energy Environ. Sci., 2011, 4, 1759-1764.

30 J. Y. Kim, D. H. Youn, K. Kang and J. S. Lee, Angew. Chem., Int. Ed., 2016, 55, 10854-10858.

31 L. Halaoui, J. Phys. Chem. C, 2016, 120, 22766-22776.

32 L. B. Bou, E. M. Marza, P. Rodenas, E. M. Barea, F. F. Santiago, S. Gimenez, E. Peris and J. Bisquert, J. Phys. Chem. C, 2013, 117, 3826-3833.

33 A. Irshad and N. Munichandraiah, J. Electrochem. Soc., 2015, 162, H235-H243.

34 Y. Surendranath, M. W. Kanan and D. G. Nocera, J. Am. Chem. Soc., 2010, 132, 16501-16509. 